\title{
Synergistic Corrosion Inhibition Effect of Rice Husk Extract and KI for Mild Steel in $\mathrm{H}_{2} \mathrm{SO}_{4}$ Solution
}

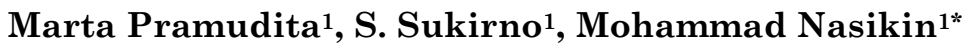 \\ ${ }^{1}$ Department of Chemical Engineering, Universitas Indonesia, Jl. Fuad Hasan, \\ Kampus UI Depok, 16424, Indonesia
}

Received: 25th January 2019; Revised: 17th June 2019; Accepted: 20th June 2019;

Available online: 30th September 2019; Published regularly: December 2019

\begin{abstract}
The corrosion inhibition of rice husk extract for bio-corrosion in mild steel in $1 \mathrm{M}$ of $\mathrm{H}_{2} \mathrm{SO}_{4}$ solution and the effect of adding potassium iodide were investigated using the weight-loss method with a variable solution temperature and various bio-inhibitor concentrations. The addition of potassium iodide can significantly increase the efficiency of rice husk extract. The highest efficiency is $95.89 \%$ at $1,250 \mathrm{ppm}$ of inhibitor concentration at a temperature of $313 \mathrm{~K}$. The inhibition efficiency of rice husk extract is synergistically increased with the addition of potassium iodide. The characteristics of the adsorption inhibitors were assessed using the Langmuir isotherm adsorption approach at all studied concentrations and temperatures. The synergy of rice husk extract and potassium iodide was examined using thermodynamic and kinetic parameters. Copyright (c) 2019 BCREC Group. All rights reserved
\end{abstract}

Keywords: Corrosion inhibitor; rice husk extract; synergy; plant extract; mild steel

How to Cite: Pramudita, M., Sukirno, S., Nasikin, M. (2019). Synergistic Corrosion Inhibition Effect of Rice Husk Extract and KI for Mild Steel in $\mathrm{H}_{2} \mathrm{SO}_{4}$ Solution. Bulletin of Chemical Reaction Engineering \& Catalysis, 14(3): 697-704 (doi:10.9767/bcrec.14.3.4249.697-704)

Permalink/DOI: https://doi.org/10.9767/bcrec.14.3.4249.697-704

\section{Introduction}

The corrosion of metals, which is deterioration due to interaction with the environment, is a natural event, and it has an effect on maintenance and repair costs in the industry [1]. Factors that can cause corrosion include temperature, solution concentration, $\mathrm{pH}$, flow rate, and so on; therefore, it is necessary to protect the metal so that corrosion can be minimized. The use of acidic solutions is extensive in the industry (e.g. acid cleaning, acid descaling, acid pickling and oil-well acidizing), which requires corrosion inhibitors that aim to withstand corrosion on metal materials [2]. The use of biocorrosion inhibitors continues to be developed

* Corresponding Author.

E-mail : mnasikin@che.ui.ac.id (M. Nasikin);

Telp: +62-21-7863516, Fax: +62-21-7863515 because it has the advantage of being biodegradable and does not contain heavy metals or other toxic compounds.

Rice husk is considered one of the most important agricultural wastes, and a great amount of research has been conducted on its use in various fields. It has a high silica content, which is a good advantage, especially for bio-corrosion inhibitors [3]. Rice husk extract (RHE) has the potential to be developed into a bio-corrosion inhibitor [4,5] and contains amorphous silica, which is safe and environmentally friendly.

Recently, researchers have been paying more attention to mixed inhibitors because of their synergistic effects. The effect of the inhibitor mixture is better than the single inhibitor effect. Further, several authors have reported that halide $\left(\mathrm{I}^{-}\right)$ions, which are known to stimulate and inhibit corrosion in acid solutions, can provide their own effective protection or can be com- 
bined with other inhibitors for mild steel in acidic solutions [6-8]. The addition of halide ions to sulphuric acid solutions containing organic inhibitors has been found to stabilize organic cation adsorption, which leads to an increase in inhibition efficiency. The synergistic effect of halides has been observed to increase in the order of $\mathrm{Cl}^{-}<\mathrm{Br}^{-}<\mathrm{I}^{-}$. Because of its large size and ease of polarization, iodide $\left(\mathrm{I}^{-}\right)$ shows the highest synergistic effect [9].

Based on the results of the study, the addition of halide compounds promotes synergy, which affects the increase in the efficiency of corrosion inhibitors. The purpose this paper is to study the synergistic corrosion inhibition between RHE and KI (iodide ion) for mild steel corrosion in $1 \mathrm{M}$ of $\mathrm{H}_{2} \mathrm{SO}_{4}$ solution.

\section{Materials and Methods}

\subsection{Material Preparation}

The mild steel used had the following composition (wt.\%): $0.54 \mathrm{Mn}, 0.05 \mathrm{Si}, 0.01 \mathrm{~S}, 0.01 \mathrm{P}$, $0.16 \mathrm{C}$ and the remaining portion was Fe. The coupon samples were grinded from 250 to 1000 grit using abrasion paper and were then washed with distilled water. They were cleaned again with acetone (Merck, 99\%) and ethanol (Merck, 70\%) and, finally, dried using a hot air blower. Weight-loss experiments were conducted on mild steel coupons with the dimensions of $3 \times 2 \times 0.5 \mathrm{~cm}$.

\subsection{Rice Husk Extract Preparation}

The rice husk was a Ciherang rice husk from Cilegon, Banten, Indonesia. The cleaned rice husk was dried in the sun for three days. Then, $100 \mathrm{~g}$ of the rice husk were burnt at 700 ${ }^{\circ} \mathrm{C}$ for two hours to isolate the silica and eliminate other substances. The burning resulted in white ash, which was then sieved with a size 60 mesh. The rice husk ash was weighed at $10 \mathrm{~g}$ and extracted by reflux at a temperature of 85 ${ }^{\circ} \mathrm{C}$ using $1 \mathrm{M}$ of $\mathrm{NaOH}$ (pellets pure Emplura ${ }^{\circledR}$, $97 \%)$ solvent for one hour. The extract was filtered to separate the residue and the filtrate. Furthermore, the filtrate was neutralised with $1 \mathrm{M}$ of $\mathrm{HCl}$ (Sigma Aldrich, 37\%) by maintaining a $\mathrm{pH}$ of 6.5 to 7 . Following this, the filtrate was deposited for 18 hours until a gel formed and when then filtered and dried at a temperature of $105{ }^{\circ} \mathrm{C}$ until reaching a constant weight.

\subsection{Weight-loss Measurements}

The cleaned and weighed samples of mild steel were immersed in corrosive media (i.e. 1 $\mathrm{M}$ of $\mathrm{H}_{2} \mathrm{SO}_{4}$ (Sigma Aldrich, 99.95\%) and bio- inhibitors of RHE with concentrations of 0.250 , 500, 750, 1000, and 1250 ppm. The KI (Sigma Aldrich, 99\%) concentration was $50 \mathrm{ppm}$ for 6 hours at temperatures of $313 \mathrm{~K}, 333 \mathrm{~K}$, and 353K. After measurement, the sample was cleaned with running water, dried and weighed to find the final mass. This procedure was performed according to NACE Recommended Practice RP-0775 and ASTM G-1 and G-4 for a weight-loss experiment. The experiment was conducted on each coupon with the same conditions, which aimed at the reliability and reproducibility of the measurements.

\subsection{Electrochemical Measurement}

The mild steel was sealed with epoxy resin in such a way that only one square of the surface area was left uncovered. The exposed surface was degreased with acetone, rinsed with distilled water and dried in warm air. Electrochemical measurements were performed in a cell containing a three-electrode assembly using Auto Lab model PGSTATx potentiostat/galvanostat, controlled by NOVA 1.1 software. In addition to the working electrode, a saturated calomel electrode and a platinum electrode were used as the reference and counter electrodes, respectively. For electrochemical measurements, the specimens were embedded in epoxy resin, leaving a working area of $1 \mathrm{~cm}^{2}$. At the beginning of the tests, the working electrode was immersed in $1 \mathrm{M}$ of $\mathrm{H}_{2} \mathrm{SO}_{4}$ for one hour to obtain a stabilised open-circuit potential. The Tafel potentiodynamic curves were recorded from -250 to $+250 \mathrm{mV}$ at a scan rate of $1 \mathrm{mVs}^{-1}$ after a steady state of 30 minutes at $298 \mathrm{~K}$.

\subsection{Surface Analysis}

After immersing the pre-treated mild steel samples in $1 \mathrm{M}$ of $\mathrm{H}_{2} \mathrm{SO}_{4}$ solution with and without $1250 \mathrm{ppm}$ of RHE for two hours at the temperatures of $313 \mathrm{~K}, 333 \mathrm{~K}$, and $353 \mathrm{~K}$, the surfaces of the mild steel samples were rinsed with Aqua Dest distilled water and ethanol and were then dried. The scanning electron microscope (SEM) energy dispersive X-ray (EDX) (Tescan Vega 3 LMU type) images of the surface morphologies of the samples were then taken.

\section{Results and Discussion}

3.1 Potentiodynamic Polarisation Measurements

The potentiodynamic polarisation method is used to determine the mild steel behaviour 
based on potential relationships and anodic/cathodic currents. If the metal interacts with a corrosive solution, then reduction and oxidation reactions can occur simultaneously on the mild steel surface. Mild steel corrosion occurs when there is an anodic current of the same magnitude as the cathodic current.

Figure 1 is a potentiodynamic polarisation curve of $1 \mathrm{M}$ of $\mathrm{H}_{2} \mathrm{SO}_{4}$ media with and without inhibitors (RHE and KI). From the measurement of potentiodynamic polarisation, the relationship between $E(\mathrm{~V})$ and $I\left(\mu \mathrm{A} . \mathrm{cm}^{-2}\right)$ is obtained, where $E$ is the potential and $I$ is the current. Potentiodynamic polarisation curves show interaction interface solutions with electrodes, which provide a certain polarisation and current. The potentiodynamic polarisation curve was extrapolated using the Tafel method to determine the corrosion inhibitory flow efficiency (IE\%, including $I_{\text {corr }}$ and $E_{\text {corr }}$; Table 1$)$. There are no definite trends observed in $E_{\text {corr }}$ values in the presence of different concentrations of inhibitors. The shift in $E_{\text {corr }}$ values is in the range of 4 to $20 \mathrm{mV}$, suggesting that it is a mixed type of inhibitor. The percentage of inhibition efficiency $(I E \%)$ is calculated using the following equation:

$$
I E \%=\frac{I_{\text {corr }(0)}-I_{\text {corr }(i)}}{I_{\text {corr }(0)}} \times 100 \%
$$

where $I_{\text {corr }(0)}$ is the corrosion current density without the addition of inhibitors $\left(\mathrm{mA} . \mathrm{cm}^{-2}\right)$ and $I_{\text {corr }(i)}$ is the corrosion current density with the addition of inhibitors (mA.cm-2).

\subsection{Weight-loss Measurements}

The corrosion of mild steel in $1 \mathrm{M}$ of $\mathrm{H}_{2} \mathrm{SO}_{4}$ in the RHE-KI mixtures was investigated at the temperature range of 313 to $353 \mathrm{~K}$ using weight-loss measurements. The calculated values of the corrosion rate (mmpy), inhibition efficiency $(I E \%)$ and surface coverage $(\theta)$ for mild steel corrosion in $1 \mathrm{M}$ of $\mathrm{H}_{2} \mathrm{SO}_{4}$ (blank) and the presence of RHE-KI in combination with different concentrations of RHE (i.e. 250, 500, 750, 1000 , and $1250 \mathrm{ppm}$ ) and $50 \mathrm{ppm}$ of $\mathrm{KI}$ at 313 to $353 \mathrm{~K}$ from the weight-loss measurement are shown in Table 1. The corrosion rate, inhibition efficiency and surface coverage were evaluated using the following ASTM G31 standard equations:

$$
C R(m m p y)=\frac{87500 \times \Delta W}{A \rho t}
$$

where $C R$ is the corrosion rate (mmpy), $\Delta W$ is the weight loss (g), $A$ is the coupon area $\left(\mathrm{cm}^{2}\right)$, $\rho$ is the density of mild steel $\left(\mathrm{g} / \mathrm{cm}^{3}\right)$ and $t$ is the immersion time (hours).

$$
\begin{aligned}
& I E \%=\left(1-\frac{C R_{\text {inh }}}{C R_{\text {blank }}}\right) \times 100 \\
& \theta=\left(1-\frac{C R_{\text {inh }}}{C R_{\text {blank }}}\right)
\end{aligned}
$$

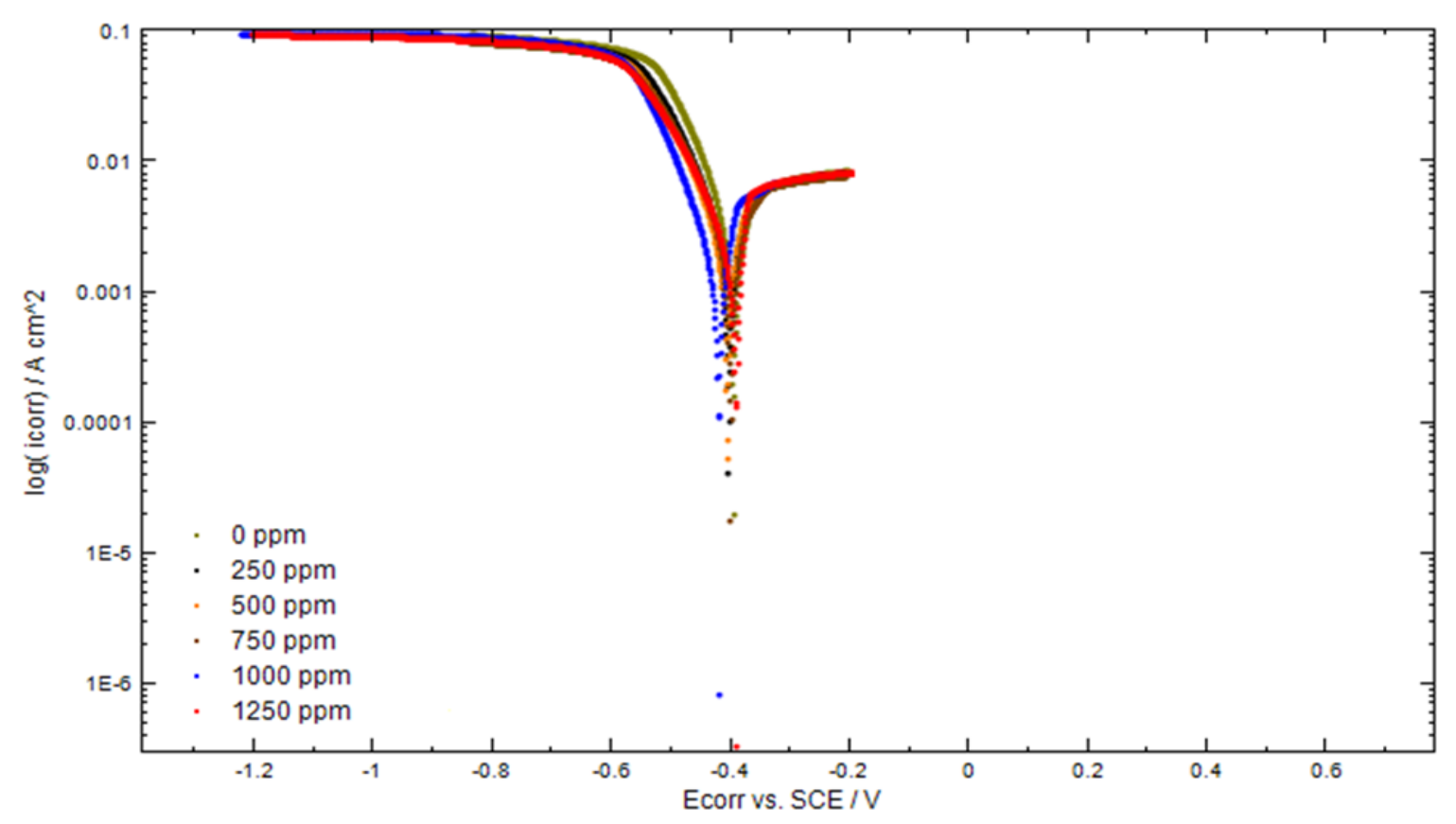

Figure 1. Potentiodynamic polarization curves for mild steel corrosion in the absence and presence of different concentration of RHE-KI 
where $C R_{\text {inh }}$ and $C R_{\text {blank }}$ are the corrosion rate with and without the inhibitor, $I E \%$ is the percentage of inhibition efficiency and $\theta$ is the coverage surface.

The results shown in Table 1 indicate that the corrosion rate increased with the increasing temperature for all concentrations. The highest corrosion rate (813.89 mmpy) was obtained at $353 \mathrm{~K}$. Based on the corrosion rate and efficiency of inhibition, RHE and KI have the ability to significantly inhibit the corrosion rate in an acidic environment. The efficiency increased with an increasing inhibitor concentration and decreased with an increasing temperature. The decrease in the efficiency of inhibition with an increasing temperature showed an increase in the solubility of the film and any corrosion product deposited on the metal surface.

Previous researchers have also found results like these with various plant extracts [10-13]. One of the possible mechanisms of corrosion in- hibition is the adsorption inhibitor on the metal surface that blocks the corrosion process. Heteroatoms such as oxygen, nitrogen, phosphorus, and sulphur enable the adsorption process because they are considered the adsorption centre $[14,15]$. In the RHE structure, oxygen and sulphur atoms have free electron pairs and phi electrons. The compound could be adsorbed because of the interaction between the free electron pairs of oxygen and sulphur at the mild steel surface. This process occurs due to the presence of the d-vacant orbital of iron as a result of iron being a transition metal. Protonated species formation occurred due to the electrostatic interaction between organic molecules and the metal surface.

\subsection{Adsorption Consideration}

On the surface of mild steel, the trend in inhibition efficiency for RHE and KI was to decrease with an increase in temperature. Ad-

Table 1. Potensiodynamic polarization parameters for mild steel in $1 \mathrm{M} \mathrm{H}_{2} \mathrm{SO}_{4}$ in the presence of different concentrations of RHE + KI

\begin{tabular}{lccccc}
\hline Concentration $(\mathrm{ppm})$ & $\begin{array}{c}-\beta_{a} \\
\left(\mathrm{mV} \cdot \mathrm{dec}^{-1}\right)\end{array}$ & $\begin{array}{c}\beta_{c} \\
\left(\mathrm{mV} \cdot \mathrm{dec}^{-1}\right)\end{array}$ & $\begin{array}{c}-E_{\text {corr }} \\
(\mathrm{mV})\end{array}$ & $\begin{array}{c}I_{\text {corr }} \\
\mathrm{mA.cm}^{-2}\end{array}$ & \multicolumn{1}{c}{$I E^{\circ}$} \\
\hline Blank & 127.64 & 188.96 & 395.70 & 59.74 & - \\
$250 \mathrm{RHE}+50 \mathrm{KI}$ & 120.88 & 136.89 & 404.05 & 42.42 & 28.99 \\
$500 \mathrm{RHE}+50 \mathrm{KI}$ & 126.55 & 118.14 & 406.05 & 37.03 & 38.01 \\
$750 \mathrm{RHE}+50 \mathrm{KI}$ & 117.64 & 112.99 & 400.39 & 34.93 & 41.52 \\
$1000 \mathrm{RHE}+50 \mathrm{KI}$ & 94.09 & 63.03 & 420.22 & 19.67 & 67.07 \\
$1250 \mathrm{RHE}+50 \mathrm{KI}$ & 81.47 & 30.06 & 391.08 & 14.97 & 74.94 \\
\hline
\end{tabular}

Table 2. Calculated values of corrosion rate (mmpy), Inhibition efficiency (\%) and degree of surface coverage $(\theta)$ for mild steel corrosion in $1 \mathrm{M} \mathrm{H}_{2} \mathrm{SO}_{4}$ for different concentration at 313-353 $\mathrm{K}$ from weight loss measurements.

\begin{tabular}{|c|c|c|c|c|c|c|c|c|c|}
\hline \multirow{3}{*}{$\begin{array}{c}\text { Concentration, } \\
\text { ppm }\end{array}$} & \multicolumn{9}{|c|}{ Corrosion rate (mmpy), Inhibition efficiency (\%) and degree of surface coverage $(\theta)$} \\
\hline & \multicolumn{3}{|c|}{$313 \mathrm{~K}$} & \multicolumn{3}{|c|}{$333 \mathrm{~K}$} & \multicolumn{3}{|c|}{$353 \mathrm{~K}$} \\
\hline & $\mathrm{CR}$ & \%E.I & $\theta$ & $\mathrm{CR}$ & \%E.I & $\theta$ & $\mathrm{CR}$ & \%E.I & $\theta$ \\
\hline Blank & 575.7 & 0 & 0 & 706.69 & 0 & 0 & 813.89 & 0 & 0 \\
\hline $250 \mathrm{RHE}$ & 222.01 & 61.44 & 0.61 & 326.64 & 53.78 & 0.54 & 546.38 & 32.87 & 0.33 \\
\hline 500 RHE & 202.12 & 64.49 & 0.64 & 296.13 & 58.09 & 0.58 & 492.63 & 39.47 & 0.39 \\
\hline 750 RHE & 186.25 & 67.65 & 0.66 & 283.27 & 59.92 & 0.59 & 482.84 & 40.68 & 0.41 \\
\hline $1000 \mathrm{RHE}$ & 175.52 & 69.51 & 0.7 & 282.22 & 60.06 & 0.6 & 459.27 & 43.57 & 0.44 \\
\hline $1250 \mathrm{RHE}$ & 171.6 & 70.2 & 0.7 & 259.8 & 63.2 & 0.63 & 416.7 & 63.2 & 0.63 \\
\hline $250 \mathrm{RHE}+50 \mathrm{KI}$ & 191.6 & 66.72 & 0.67 & 313.86 & 55.59 & 0.56 & 527.01 & 35.25 & 0.35 \\
\hline $500 \mathrm{RHE}+50 \mathrm{KI}$ & 178.13 & 69.06 & 0.69 & 243.24 & 65.58 & 0.66 & 461.98 & 43.24 & 0.43 \\
\hline $750 \mathrm{RHE}+50 \mathrm{KI}$ & 162.04 & 71.85 & 0.72 & 190.21 & 73.08 & 0.73 & 401.07 & 50.72 & 0.51 \\
\hline $1000 \mathrm{RHE}+50 \mathrm{KI}$ & 148.66 & 74.18 & 0.74 & 173.18 & 75.49 & 0.75 & 331.6 & 59.26 & 0.59 \\
\hline $1250 \mathrm{RHE}+50 \mathrm{KI}$ & 121.6 & 78.88 & 0.79 & 161.29 & 77.18 & 0.77 & 280.98 & 65.48 & 0.65 \\
\hline
\end{tabular}


sorption isotherms provided more information in understanding the nature of the interaction between inhibitor molecules and the surface of metal substrates, therefore, the Langmuir isotherm adsorption was used to describe the interaction. The weight-loss method was used to obtain the degree of surface coverage $(\theta)$. The Langmuir adsorption isotherm equation [16] is as follows:

$$
\frac{C}{\theta}=\frac{1}{K_{a d s}}+C
$$

where $C$ is the concentration of the inhibitor (ppm), $\theta$ is the surface coverage and $K_{a d s}$ is the adsorption equilibrium constant. The Langmuir isotherm assumes that a solid surface has a fixed number of adsorption sites and that each site has one adsorbed species. To determine the value of $K_{a d s}, \log C / \theta$ is plotted against $C$, which is shown in Figure 1.

The value of $K_{a d s}$ is obtained from the linear results of the plot $(C / \theta$ vs $C$ ) and shows the strength between the adsorbate and adsorbent. A greater $K_{a d s}$ value indicates that the adsorption will be efficient and effective. The value of $K_{a d s}$ from the calculation results is shown in Table 3. A higher temperature decreases the $K_{a d s}$ value, which indicates that the strength between the adsorbate and adsorbent decreases with increasing temperature [17].

\subsection{Kinetics and Thermodynamic Studies}

In an acidic solution, the corrosion rate is related to the temperature according to the Arrhenius equation, according to which, the logarithm of the corrosion rate $(\log C R)$ is a linear function with $1 / T[16,18]$ :

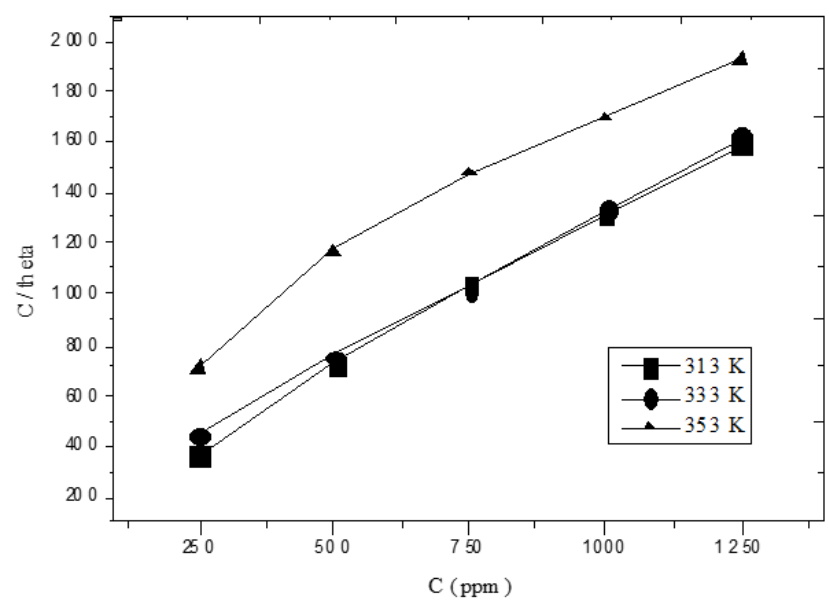

Figure 2. Langmuir isotherm for the adsorption of RHE+KI on mild steel in $1 \mathrm{M} \mathrm{H}_{2} \mathrm{SO}_{4}$ at $313 \mathrm{~K}$, $333 \mathrm{~K}$ and $353 \mathrm{~K}$

$$
\log C R=\log A-\frac{E_{a}}{2.303 R T}
$$

where $C R$ is the corrosion rate, $E_{a}$ is the activation energy $(\mathrm{kJ} / \mathrm{mol}), A$ is the Arrhenius constant, $R$ is the molar gas constant and $T$ is the absolute temperature (K). The activation energy was determined using the slopes of $\log C R$ versus the $1 / T$ graph depicted in Figure 2.

The kinetic parameter of activation energy is important for studying the inhibitive mechanism. If the $E_{a}$ value increases, it can be interpreted as a physical adsorption; conversely, if the $E_{a}$ value decreases, chemisorption is possible. Table 2 shows that the tendency is towards chemisorption.

The free energy of adsorption $\left(\Delta G^{o} a d s\right)$ values were obtained from the intercept of Figure 1. The equation is as follows [19]:

$$
\Delta G_{a d s}^{o}=-R \times T \ln \left(55.5 \times K_{a d s}\right)
$$

where $R$ is the gas constant, $T$ is the absolute temperature and $\Delta G^{o}$ ads is the standard free energy of adsorption (kJ/mol).

The calculated value of $-\Delta G_{a d s}^{o}$ can be seen in Table 4. It shows that the process takes place spontaneously, meaning that the formation of the film layer by RHE and KI on the surface of mild steel takes place immediately. The value of $-\Delta G^{o}{ }_{a d s}$ ranges from $10.66 \mathrm{~kJ} / \mathrm{mol}$ to $11.243 \mathrm{~kJ} / \mathrm{mol}$.

\subsection{Surface Analysis}

The surface morphology of mild steel samples before immersion in the test solution and the mild steel samples in $1 \mathrm{M}$ of $\mathrm{H}_{2} \mathrm{SO}_{4}$ solution

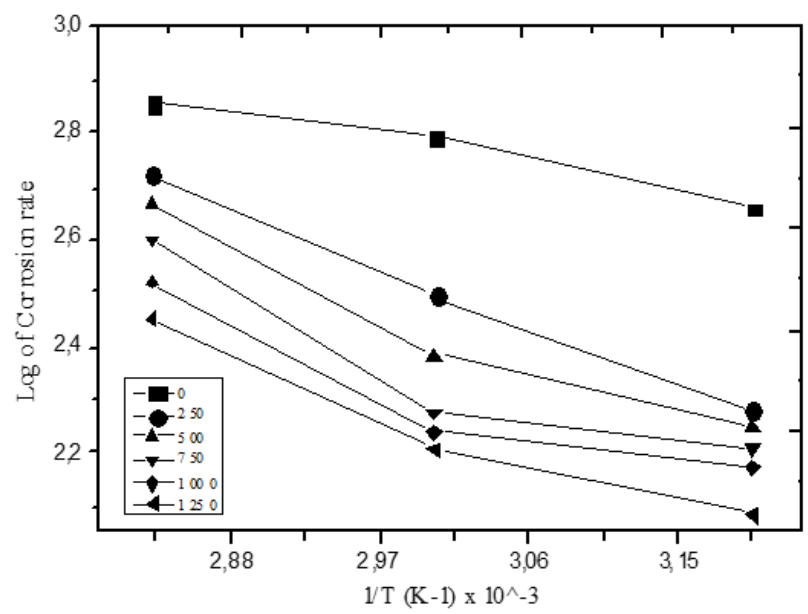

Figure 3. Arrhenius plot for mild steel corrosion in $1 \mathrm{M} \mathrm{H}_{2} \mathrm{SO}_{4}$ in the absence and present $\mathrm{RHE}$ and $\mathrm{KI}$ 


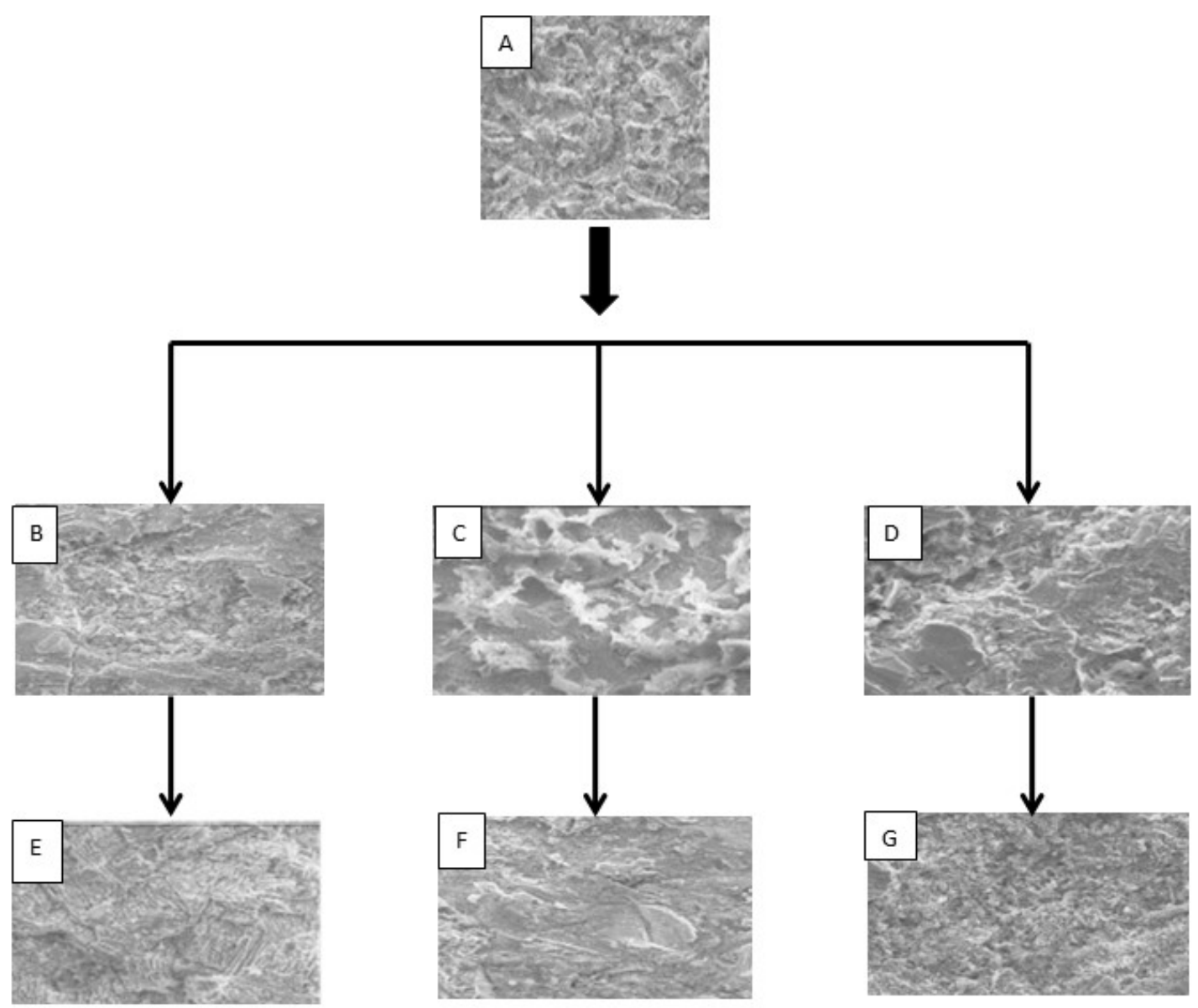

Figure 4. SEM surface morphologies of mild steel before immersed (A), Mild steel after immersed 2 hours without RHE + KI at $313 \mathrm{~K}(\mathrm{~B}), 333 \mathrm{~K}(\mathrm{C}), 353 \mathrm{~K}$ (D). Mild steel after immersed 2 hours with $\mathrm{RHE}+\mathrm{KI}$ at $313 \mathrm{~K}(\mathrm{E}), 333 \mathrm{~K}(\mathrm{~F}), 353 \mathrm{~K}(\mathrm{G})$

Table 3. $K_{\text {ads }}$ Values

\begin{tabular}{ccc}
\hline Temperature, $\mathrm{K}$ & $K_{\text {ads }}$ & R-square \\
\hline 313 & 1.0835 & 0.99 \\
333 & 0.9181 & 0.99 \\
353 & 0.8307 & 0.99 \\
\hline
\end{tabular}

Table 4. Activation energy for mild steel in $1 \mathrm{M}$ $\mathrm{H}_{2} \mathrm{SO}_{4}$

\begin{tabular}{lc}
\hline \multicolumn{1}{c}{ Systems/Concentration } & $\begin{array}{c}\text { Activation energy, } \\
\text { Ea (kJ/mol) }\end{array}$ \\
\hline Blank & 0.959 \\
250 ppm RHE +50 ppm KI & 2.7906 \\
500 ppm RHE + 50 ppm KI & 2.6115 \\
750 ppm RHE + 50 ppm KI & 2.4685 \\
1000 ppm RHE + 50 ppm KI & 2.1863 \\
1250 ppm RHE + 50 ppm KI & 2.2961 \\
\hline
\end{tabular}

Table 5. $\Delta \mathrm{G}^{\mathrm{o}}$ ads values

\begin{tabular}{cc}
\hline Temperature, $\mathrm{K}$ & $\Delta \mathrm{G}$ ads, $\mathrm{kJ} / \mathrm{mol}$ \\
\hline 313 & -10.6605 \\
333 & -10.8830 \\
353 & -11.2431 \\
\hline
\end{tabular}

Table 6. Synergism parameter $\left(S_{1}\right)$ for different concentration RHE from weight loss measurement at temperature $313 \mathrm{~K}, 333 \mathrm{~K}$, and $353 \mathrm{~K}$

\begin{tabular}{cccc}
\hline \multirow{2}{*}{$\begin{array}{c}\text { RHE concen- } \\
\text { trations, ppm }\end{array}$} & \multicolumn{3}{c}{ Tynergistic Parameter $\left(S_{1}\right)$} \\
\cline { 2 - 4 } & 313 & 333 & 353 \\
\hline 250 & 0.86 & 0.93 & 0.98 \\
500 & 0.82 & 1.02 & 0.88 \\
750 & 0.89 & 1.10 & 0.99 \\
1000 & 0.87 & 1.15 & 1.12 \\
1250 & 1.04 & 1.32 & 0.87 \\
\hline
\end{tabular}


in the absence and presence of RHE-KI after 2 hours of immersion time at a concentration of $1250 \mathrm{ppm}$ at temperatures of $313 \mathrm{~K}, 333 \mathrm{~K}$, and $353 \mathrm{~K}$ were analyzed. Mild steel surfaces that are immersed in acidic media in the absence of RHE and KI (Figure 4.B-D) show corrosion holes, which are defined as high levels of local corrosion by the acidic media. These corrosion holes were observed not on the surface of the substrate, where the extracts were present in the $\mathrm{H}_{2} \mathrm{SO}_{4}$ solution (Figure 4.E-G). The surface morphology of the sample immersed in an acid solution containing RHE and KI was observed to be very similar in topography to the substrate before being immersed in $1 \mathrm{M}$ of $\mathrm{H}_{2} \mathrm{SO}_{4}$ (4.A) solution. This supports the argument that the formation of a protective film by the extract on mild steel serves as a barrier that limits the degree of corrosion by acid solution.

\subsection{Synergistic Effect}

Synergy is the improved effect of the combined action of a compound that has better results than the individual components. Synergistic inhibition is the most effective way to increase the ability of inhibitors to inhibit corrosion and reduce the use of inhibitors in acidic media. Synergistic inhibitors work because of interactions between inhibitor components or interactions between inhibitors and one of the ions in aqueous solutions. The use of iodide ions is often attributed to the radius of a large atom and the high electronegativity and hydrophobicity compared to other halide ions [20].

The inhibitory efficiency with the addition of $\mathrm{KI}$ is higher than that using RHE only - the result of which has been found by previous researchers. The relationship between the efficiency and concentration of each inhibitor added by $\mathrm{KI}$ is shown in Table 2. The mechanism of the reaction that occurs in the synergy process between RHE and KI can be described as follows [21]:

$$
\begin{aligned}
& \mathrm{Fe}+\mathrm{H}_{2} \mathrm{O}+\mathrm{X}^{-} \leftrightarrow(\mathrm{FeXOH})_{\text {ads }}+\mathrm{H}^{+}+\mathrm{e}^{-} \\
& (\mathrm{FeOH})^{-} \text {ads } \leftrightarrow(\mathrm{FeXOH})^{+}+\mathrm{e}^{-} \\
& (\mathrm{FeXOH})+\mathrm{H}^{+} \leftrightarrow \mathrm{Fe}^{2+}+\mathrm{X}^{-}+\mathrm{H}_{2} \mathrm{O}
\end{aligned}
$$

where X represents $\mathrm{I}^{-}$.

It is generally accepted that the presence of halide ions in acidic media synergistically increases the inhibitory efficiency of some organic compounds. Anions can increase the adsorption of organic cations in a solution by forming a bridge between the metal surface and the positive end of the organic inhibitor. Synergism of corrosion inhibition results from an increase in surface coverage arising from the interaction of ion pairs between organic cations and anions.

To further confirm whether there is synergy, we must determine the synergistic parameters to describe the inhibitory behaviour of the combination of RHE and KI. In general, for the interaction of Inhibitors 1 and 2, the synergism $\left(S_{1}\right)$ parameter is defined as follows [22]:

$$
\begin{aligned}
& S_{1}=\frac{1-\theta_{1+2}}{1-\theta_{1+2}^{\prime}} \\
& \theta_{1+2}=\left(\theta_{1}+\theta_{2}\right)-\left(\theta_{1} \theta_{2}\right)
\end{aligned}
$$

where $\theta_{1}$ is the surface coverage of $\mathrm{KI}, \theta_{2}$ is the surface coverage of RHE and $\theta^{\prime}{ }_{1+2}$ is the surface coverage of RHE and KI. If $S_{1}=1$, it means that the RHE and KI inhibitors have no effect on each other and that they absorb the metal interface/solution independently; in addition, $S_{1}>1$ indicates that a synergistic effect occurs, whereas $S_{1}<1$ means an antagonistic effect occurs. The results of the calculation of the synergistic effect can be seen in Table 6. At the temperature of $313 \mathrm{~K}$, a synergistic effect occurred at the concentration of RHE of 1250 $\mathrm{ppm}$. At the temperature of $333 \mathrm{~K}$, a synergistic effect occurred starting at concentrations of $500,750,1000$, and $1250 \mathrm{ppm}$. At the temperature of $353 \mathrm{~K}$, a synergistic effect only occurs at a concentration of $1000 \mathrm{ppm}$.

\section{Conclusion}

As a synergistic bio-corrosion inhibitor, RHE and KI have been observed as effective for the corrosion of mild steel in $\mathrm{H}_{2} \mathrm{SO}_{4}$ solution. The inhibition efficiency increases with increasing concentrations of RHE and KI, and the addition of KI enhances the inhibition efficiency significantly. The adsorption of RHE and KI onto a mild steel surface was a spontaneous process. The RHE was synergized via KI acting as a mixed-type inhibitor.

\section{Aknowledgement}

This work is supported by Hibah TADOK 2018 No. 1353/UN2.R3.1/ HKP.05.00/2018 funded by DRPM Universitas Indonesia.

\section{References}

[1] Umoren, S.A., Eduok, U.M. (2016). Application of carbohydrate polymers as corrosion inhibitors for metal substrates in different media: A review. Carbohydr. Polym., 140: 314341.

[2] Rani, B.E.A., Basu, B.B.J. (2012). Green Inhibitors for Corrosion Protection of Metals 
and Alloys: An Overview. International Journal of Corrosion, 2012: 1-15.

[3] Ahmed, N.M., Abd El-Gawad, W.M., Mohamed, M.G., Elshami, A.A. (2016). Introducing rice husk after utilizing new technology as anticorrosive pigments in organic coatings. Progress in Organic Coatings, 101: 309-321.

[4] Shen, Y. (2017). Rice husk silica derived nanomaterials for sustainable applications. Renewable and Sustainable Energy Reviews, 80: 453-466.

[5] Pramudita, M., Sukirno, S., Nasikin, M. (2018). Rice Husk Extracts Ability to Reduce the Corrosion Rate of Mild Steel. International Journal of Chemical Engineering and Applications, 9(4): 143-146.

[6] Hao, Y., Sani, L.A., Ge, T., Fang, Q. (2017). The synergistic inhibition behaviour of tannic acid and iodide ions on mild steel in $\mathrm{H}_{2} \mathrm{SO}_{4}$ solutions. Corrosion Science, 123: 158-169.

[7] El Nemr, A., Moneer, A.A., Khaled, A., El Sikaily, A., El-Said, G.F. (2014). Modeling of synergistic halide additives' effect on the corrosion of aluminum in basic solution containing dye. Materials Chemistry and Physics, 144(1-2): 139-154.

[8] Ituen, E., James, A., Akaranta, O., Sun, S. (2016). Eco-friendly corrosion inhibitor from Pennisetum purpureum biomass and synergistic intensifiers for mild steel. Chinese Journal of Chemical Engineering, 24(10): 14421447.

[9] Shaju, K.S., Thomas, K.J., Raphael, V.P., Paul, A. (2012). Synergistic Effect of KI on Corrosion Inhibition of Mild Steel by Polynuclear Schiff Base in Sulphuric Acid. ISRN Corrosion, 2012: 1-8.

[10] Zhao, J., Duan, H., Jiang, R. (2015). Synergistic corrosion inhibition effects of coptis extract or berberine and thiourea on the corrosion of mild steel. International Journal of Electrochemical Science, 10: 2716-2739.

[11] Sankar, S.A., Rameshkumar, S. (2014). Synergistic effect on inhibition efficiency of coconut husk fibre essence in controlling corrosion of mild steel. Bangladesh Journal of Scientific and Industrial Research, 49: 185-188.

[12] Umoren, S.A., Solomon, M.M. (2015). Effect of halide ions on the corrosion inhibition efficiency of different organic species - A review. Journal of Industrial and Engineering Chemistry, 21: 81-100.

[13] Li, X., Deng, S., Fu, H., Xie, X. (2014). Synergistic inhibition effects of bamboo leaf ex- tract/major components and iodide ion on the corrosion of steel in $\mathrm{H}_{3} \mathrm{PO}_{4}$ solution. Corrosion Science, 78: 29-42.

[14] Yadav, M., Behera, D., Kumar, S., Yadav, P. (2015). Experimental and Quantum Chemical Studies on Corrosion Inhibition Performance of Thiazolidinedione Derivatives for Mild Steel in Hydrochloric Acid Solution. Chemical Engineering Communications, 202(3):303315.

[15] Yadav, M., Kumar, S., Gope, L. (2014). Experimental and theoretical study on amino acid derivatives as eco-friendly corrosion inhibitor on mild steel in hydrochloric acid solution. Journal of Adhesion Science and Technology, 28(11): 1072-1089.

[16] Khadom, A.A., Abd, A.N., Ahmed, N.A. (2018). Xanthium strumarium leaves extracts as a friendly corrosion inhibitor of low carbon steel in hydrochloric acid: Kinetics and mathematical studies. South African Journal of Chemical Engineering, 25: 13-21.

[17] Li, X., Tang, L., Li, L., Mu, G., Liu, G. (2006). Synergistic inhibition between ophenanthroline and chloride ion for steel corrosion in sulphuric acid. Corrosion Science, 48(2): 308-321.

[18] Akalezi, C.O., Oguzie, E.E., Ogukwe, C.E., Ejele, E.A. (2015). Rothmannia longiflora extract as corrosion inhibitor for mild steel in acidic media. International Journal of Industrial Chemistry, 6(4): 273-284.

[19] Bentiss, F., Lebrini, M., Lagrenée, M. (2005). Thermodynamic characterization of metal dissolution and inhibitor adsorption processes in mild steel/2,5-bis(n-thienyl)-1,3,4thiadiazoles/hydrochloric acid system. Corrosion Science, 47(12): 2915-2931.

[20] Oguzie, E.E., Okolue, B.N., Ebenso, E.E., Onuoha, G.N., Onuchukwu, A.I. (2004). Evaluation of the inhibitory effect of methylene blue dye on the corrosion of aluminium in hydrochloric acid, Materials Chemistry and Physics, 87(2-3): 394-401.

[21] Eduok, U.M., Umoren, S.A., Udoh, A.P. (2012). Synergistic inhibition effects between leaves and stem extracts of Sida acuta and iodide ion for mild steel corrosion in 1M H2SO4 solutions. Arabian Journal of Chemistry, 5(3): 325-337.

[22] Umoren, S.A., Solomon, M.M. (2017). Synergistic corrosion inhibition effect of metal cations and mixtures of organic compounds: A Review. Journal of Environmental Chemical Engineering, 5(1): 246-273.

Selected and Revised Papers from The $3^{\text {rd }}$ International Conference on Chemical and Material Engineering (ICCME) 2018 (http://iccme2018.undip.ac.id) (Diponegoro University, by 19th-20th September 2018) after Peer-reviewed by Scientific Committee of ICCME 2018 and Peer-Reviewers of Bulletin of Chemical Reaction Engineering \& Catalysis 